\title{
Proyecto fotográfico Auschwitz: El escenario del horror
}

\author{
Auschwitz Photographic Project: The Horror Scene \\ Inmaculada Sánchez Macías*
}

\begin{abstract}
Resumen
El proyecto educativo Auschwitz: El escenario del horror se desarrolla entre 2017 y 2019 , desde su gestación hasta las exposiciones de fotografías y charlas-coloquio en el que se ha enmarcado. Forma parte de una enseñanza informal, en el que los aprendizajes están determinados por situaciones cotidianas del contacto social, que no está organizado o administrado por una estrategia educativa determinada. Es una experiencia que se desarrolla en ámbitos relajados, como en el caso de asociaciones culturales o ayuntamientos. El autor de las fotografías desempeña el símbolo de la mirada del visitante, que, a través de su cámara, nos enseña el campo de muerte de Auschwitz, describiéndonos los sentimientos y las sensaciones que allí pudieron acontecer en los primeros años de la década de los 40 .
\end{abstract}

Palabras clave: Educación informal. Fotografía. Holocausto. Aprendizaje informal.

\begin{abstract}
The educational project Auschwitz: The Horror Scene takes place between 2017 and 2019, from its gestation to the photo exhibitions and talks-colloquium in which it has been framed. It is part of an informal teaching, in which learning is determined by everyday situations of social contact, which is not organized or managed by a specific educational strategy. It is an experience that takes place in relaxed settings, as in the case of cultural associations or city councils. The author of the photographs plays the symbol of the visitor's gaze, who, through his camera, shows us the Auschwitz death camp, describing the feelings and sensations that could occur there in the early years of the decade of the 40 .
\end{abstract}

Key words: Informal education. Photography. Holocaust. Informal learning.

\section{Introducción}

En consonancia con la reflexión de Bauman (2007), el objetivo de la educación "es formar ciudadanos que recuperen el espacio público de diálogo y sus derechos democráticos, para así ser capaces de controlar el futuro de su entorno y el suyo propio" (Bauman, 2007, p. 48). En este contexto de diálogo debe desarrollarse la educación para toda la vida (Knowles, 1981; Hiemstra, 1981) como competencia presente en los espacios formales, no formales e informales.

\footnotetext{
* Universidad de Valladolid•ORCID 0000-0002-8908-9333• inmaculada.sanchez.macias@uva.es
}

Sánchez-Macías, I. (2020). Proyecto fotográfico Auschwitz: El escenario del horror. CLIO. History and History teaching, 46, 99-109. https://doi.org/10.26754/ojs clio/clio.2020465299. Recibido: 10/9/2020. Aceptado: 4/12/2020. 
Desde hace unos años se están dedicando muchos recursos al tema de la educación informal (Cuadrado, 2017), a través de distintas ópticas: aprendizaje en el trabajo, formas no escolares de educación, estudio de contextos informales como la familia, los medios o el aprendizaje incidental, así como el diseño de situaciones informales. A la vez, se han desarrollado recursos teóricos como la aproximación a las innovaciones y conceptos en disciplinas tradicionales no pedagógicas (como Sociología, Antropología, Psicología, Filosofía y Economía), o nuevos enfoques como la Teoría de la Actividad (Vygostky, 1978; Leontiev 1972; Luria 1979; Gal'perin 1992; Engeström, Miettinen, Reijo y Punamäki, Raija-Leena, 1999), o aproximaciones narrativas y contextuales, entre otros.

$Y$ en este marco informal de la educación se llevan a cabo programas y proyectos educativos que se crean con el fin de educar a diversos colectivos a través del uso de herramientas, como internet, el cine, las charlas-coloquio, los debates, las artes plásticas como la fotografía, que suplen las carencias de otras enseñanzas. $Y$ en cuanto a la fotografía, nos recuerda Sontag (1996), que "el resultado más imponente de la empresa fotográfica es darnos la sensación de que podemos apresar el mundo entero en nuestras cabezas, como una antología de imágenes. Coleccionar fotografías es coleccionar el mundo" (Sontag, 1996, p.13).

Por ello, el proyecto Auschwitz: El escenario del horror nace con la constatación de que la representación del Holocausto en la enseñanza formal es mera anécdota, a través del uso de libros y no invita a reflexionar y a indagar. Sin embargo, en un ámbito informal, utilizando la fotografía y las charlas-coloquio como herramientas pedagógicas, se demuestra que lleva a los participantes por la senda de la formación en valores cívicos democráticos y por el fomento del pensamiento crítico, además de formar ciudadanos responsables y activos en la esfera pública y a lo largo de toda la vida.

\section{La fotografía en la educación informal}

La educación informal, y más concretamente el aprendizaje informal, se ha identificado con ese aprendizaje que se produce en el lugar de trabajo, ya que se tiene en cuenta que es la actividad principal en la edad adulta. Pero hoy en día esa concepción ha dado un giro, incluso en países como Reino Unido, que ha sido uno de los que más ha 
defendido ese concepto limitado del aprendizaje informal en muchas publicaciones (McLean y Wilson, 2009; Marsick y Watkins, 1990; Hager y Halliday, 2009; Le Clus, 2011).

Para algunos autores (Schugurensky, 2006) el aprendizaje informal puede ser clasificado en tres modalidades: el aprendizaje autodirigido, el incidental y el que se produce por la socialización; estos aprendizajes se distinguen entre otros aspectos, por el ser conscientes (aurodirigido), o no son casi nunca conscientes (incidental), o en pocas ocasiones. Pero otros autores como Marsick y Watkins (1990) diferencian entre el informal y el incidental como formas distintas. Incluso, se tiene en cuenta que la educación informal parece más una construcción externa teórica en la que la propia persona no siempre es consciente cuando se produce incidentalmente o en determinadas formas de su vida cotidiana (Rodriguel-Illera y Kaechele, 2009). Esta distinción tripartita (formal, no formal e informal) pasó a asociarse además a un nuevo concepto que ha aparecido también en el ámbito de la política educativa: el del aprendizaje permanente o a lo largo de toda la vida (Knowles, 1981; Hiemstra, 1981).

En los programas informales se plantea una metodología de indagación e investigación que implica un mayor énfasis en la búsqueda, construcción y discusión del conocimiento (Asensio, 1994; Asensio y Pol, 1999, 2001 y 2008). La propuesta educativa del aprendizaje informal trata de responder a las necesidades psicológicas básicas en las que se basa la motivación intrínseca (Deci y Ryan, 1985, 1991; Deci y Moller, 2005), a lo que Csikszentmihalyi, (1975), Csikszentmihalyi, Abuhamedeh y Nakamura (2005) denominaron flow.

La fotografía es, junto a las nuevas tecnologías y las redes sociales, especialmente interesante en el marco de una sociedad basada en el conocimiento que exige que el aprendizaje sea una actividad constante a lo largo de toda la vida. De hecho, aprendemos informalmente de manera constante y la mayor parte del conocimiento que utilizamos en la vida cotidiana no lo hemos adquirido en la escuela.

Bourdieu (2003), afirma que:

Nada opone más directamente a la imagen corriente de la creación artística que la actividad del fotógrafo aficionado, quien a menudo exige a la cámara fotográfica hacer en su lugar el mayor número posible de operaciones, identificando el grado de perfección del aparato que utiliza con su grado de automatismo. Sin embargo, 
aun cuando la producción de la imagen sea enteramente adjudicada al automatismo de la máquina, su toma sigue dependiendo de una elección que involucra valores estéticos y éticos: si, de manera abstracta, la naturaleza y los progresos de la técnica fotográfica hacen que todas las cosas sean objetivamente "fotografiables", de hecho, de la infinidad teórica de las fotografías técnicamente posibles, cada grupo selecciona una gama finita y definida de sujetos, géneros y composiciones. (p. 43).

Bourdieu (2003) también nos propone que la estética popular expresada en las fotografías y en los juicios que se hacen sobre ellas solo puede depender de las funciones sociales que se atribuyen a las practicas fotográficas. Es por ello que "toda fotografía es la encrucijada donde convergen miradas diversas: La mirada de quien realiza la fotografía. La mirada de lo fotografiado. La mirada de quien usa o se sirve de esa fotografía con un fin determinado. La mirada de quien mira esa foto" (Opitz, 2007, p. 237).

\section{Proyectos educativos sobre el Holocausto}

A un nivel internacional ha habido diversas iniciativas cuya finalidad se ha centrado en la recuperación de la memoria de los campos de concentración. Así, por ejemplo, nace la International Holocaust Remembrance Alliance (IHRA), que en 1998 aparece como una propuesta intergubernamental para la promoción, el recuerdo de las víctimas y la investigación de lo ocurrido y cómo se estaba enseñando en los distintos países que forman dicha institución. Este proyecto impulsó otros que le sucedieron, como el Foro Internacional de Estocolmo sobre el Holocausto (2000), en el que España participó desde 2008.

En el 2001 aparece The Education Working Group (EWG), encargado de las tareas de asesoramiento y buenas prácticas de los países firmantes que pidiesen su ayuda de cara a implementar la enseñanza del Holocausto en el currículo, poniendo a su disposición la experiencia de pedagogos que promovieran el proyecto de forma adecuada (Izquierdo, 2017).

Cuatro años después, las Naciones Unidas declaran el 25 de enero como Día Internacional de Conmemoración de las víctimas del Holocausto, coincidiendo en fecha con la liberación de los presos de Auschwitz-Birkenau en 1945. Además, la UNESCO en 2005 publica la Resolución 60/7 en la que insta a la enseñanza del 
Holocausto a través de su plataforma online, con material pedagógico para uso de cualquier persona, incluyendo el aprendizaje informal.

Mortimer y Shonick (2010) explican que la Salzburg Global Seminar se celebró con el fin de concienciar sobre la importancia de la enseñanza del Holocausto a edades tempranas como forma de prevención de la homofobia, antisemitismo, racismo, odio o genocidio que puedan aparecer en las sociedades actuales. $Y$ desde este encuentro surgieron distintos grupos de investigación, como el Salzburg Iniciative y el U.S. Holocaust Memorial Museum, que tuvo la finalidad de adaptar la pedagogía del Holocausto en los países que no lo sufrieron directamente. Esta investigación sienta las bases para la idea de enseñar el Holocausto en ámbitos más amplios que en la propia enseñanza formal y el currículo, contextos en los que se puedan relacionar con los derechos humanos (VV.AA., 2013) y se considera que "el Holocausto no fue solamente un crimen contra los judíos, sino que fue un crimen contra toda la humanidad" (Arendt, 2003, p.9).

La realidad con que nos encontramos hoy día es que las instituciones no se han parado a evaluar la enseñanza del Holocausto como debieran y, por el contrario, ha provocado distintos estereotipos. Por ejemplo, el Salzburg Global Seminar constató que existen dos versiones sobre el Holocausto en Austria: la que se impulsa desde el Ministerio de Educación (formal), en la que se enseña que Austria colaboró con la Alemania nazi en la deportación y ejecución de judíos; y por otro lado, el discurso que sigue imperando en la mayoría de familias (no formal e informal) que, debido a la cercanía de los hechos y la carga emocional, afirma que los austriacos fueron obligados a participar en el Holocausto y que, por tanto, fueron también víctimas de los nazis (Mortimer y Shonick, 2010).

Por ello, en un equilibrio entre la enseñanza formal e informal se puede generar una idea crítica de lo sucedido. Han aparecido en los distintos países proyectos educativos dentro de la enseñanza no formal e informal, como el Memorial de la Shoah de París, en el que se realizan talleres y seminarios de sensibilización para concienciar a los más jóvenes sobre el horror del Holocausto. El Holocaust Memorial Museum en EEUU posee una página web de información y actividades para cualquier usuario interesado en el tema. O el Museo Estatal de Auschwitz-Birkenau, del que parte nuestro proyecto, 
que se encarga de proporcionar enlaces a publicaciones y material en distintos idiomas para la enseñanza y sensibilización del exterminio en Auschwitz (Polonia).

Este proyecto que se presenta, denominado Auschwitz: El escenario del horror, parte de una persona con inquietudes fotográficas y por viajar, Antonio Vallano (Valladolid, 1971). Su empeño de tomar el pulso a los países que viaja a través de la captura de imágenes se le hace imprescindible para entender el estado en que se encuentra en la actualidad ese país. En diciembre de 2017 viaja a Cracovia (Polonia) para fotografiar la ciudad y sus encantos. Comienza en la plaza Szczepanski y acaba el día en el complejo de Auschwitz I, acompañado por una guía, quien avisa al grupo de zonas que están vetadas a las fotografías por respeto. Después la visita continúa en el complejo Auschwitz II (Birkenau). Realiza un total de 155 fotografías utilizando una cámara Reflex FX Nikon D750, con un objetivo AF Nikkor 24-85mm f/2.8-4 D IF que permite gran apertura y maneja un buen rango de distancias focales, 4 baterías de repuesto y gamuzas de microfibra para secar la inevitable lluvia de diciembre en Polonia.

Aquellas fotografías se realizaron en un principio como recuerdo de la visita a aquellos lugares, como en otras ocasiones. Sin embargo, una vez revisadas fuera de aquel contexto se fraguó la necesidad de enseñar cómo se vivió el horror en aquel campo de exterminio. Por ello nació el proyecto fotográfico Auschwitz: El escenario del horror, comenzando en su blog de ochenta y siete mil visitas, (http://antoniovallano.blogspot.com) continuando con la exposición de una selección de sus fotografías a través de un audiovisual en la Asociación Fotográfica Vallisoletana (2018) o la exposición de esta obra en el centro cívico "José Luis Mosquera" de Valladolid, ante un público especializado en la fotografía y el audiovisual, que mantuvo un amplio debate sobre el tema tras la reposición del audiovisual de las fotografías y que salió impresionado de las imágenes con poder pedagógico.

Hay que tener en cuenta que la diferencia entre los procesos de enseñanza formales, no formales e informales es el grado de estructuración, es decir, el grado en que se encuentran planificados y dirigidos hacia metas concretas, además de su rigidez o flexibilidad, linealidad de su estructura, entre otros aspectos. 
No obstante, los objetivos que se propusieron en este proyecto fueron: 1) usar fuentes primarias como herramientas de acercamiento al Holocausto que se produjo en Auschwitz y 2) promover a través de las imágenes la reflexión sobre el genocidio cometido por los nazis y su traslado a la actualidad y los grupos susceptibles.

\section{Resultados}

Algunos de los resultados de esta propuesta se detallan a continuación:
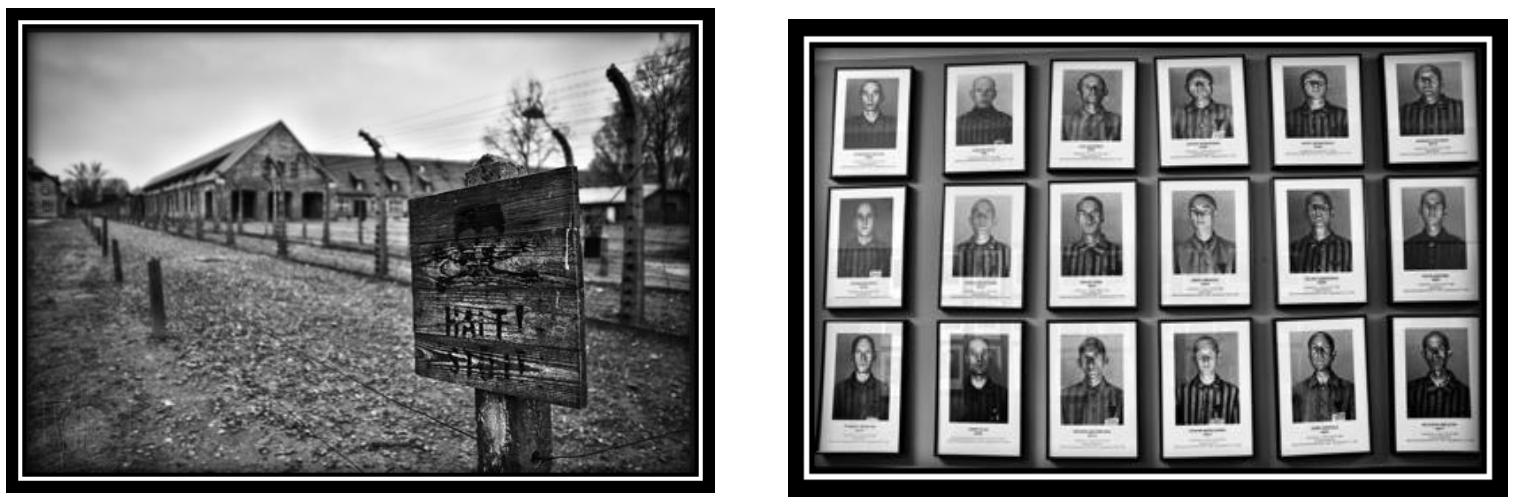

Figura 1. Fotografías "Halt" (izquierda) y "Prisioneros" (derecha) Autor: Antonio Vallano (2017), https://www.flickr.com/photos/antonio vallano/albums/72157694587585382

"Todo te advierte de que no eres libre. Parece evidente que la única manera de salir de aquí era muerto. $Y$ eso, exactamente, es lo que les sucedió a más de 70.000 personas, en los poco más de cuatro años que estuvo en funcionamiento el complejo Auschwitz l".

"Meses, semanas, días o incluso horas...cada uno duraba lo que podía en este infierno. Esta máquina de muerte, perfectamente engrasada, se encargó de documentar gran parte de sus atrocidades. Así, podemos conocer los rostros de las víctimas, mirar a los ojos de los que ya no están y prometerles que haremos todo lo posible para que nunca nadie tenga que volver a pasar por lo mismo" Antonio Vallano (2017). 

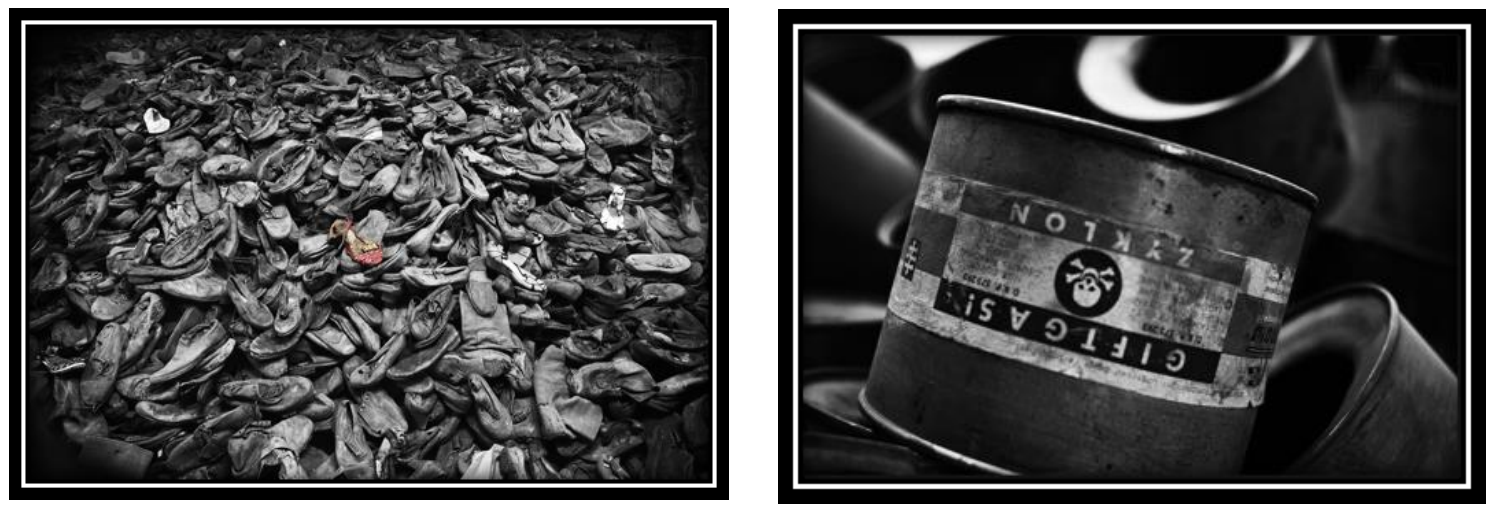

Figura 2.

Fotografías "La chica de los zapatos rojos" (izquierda) y Sin título (derecha). Autor: Antonio Vallano (2017), https://www.flickr.com/photos/antonio vallano/albums/72157694587585382

"La expresión inglesa To be in his shoes (literalmente estar en tus zapatos), significa ponerse en el lugar de otra persona, estar en su situación. Ahora, mirando las montañas de zapatos apilados puedo imaginar la historia de cada una de las personas que lo calzaban. Veo zapatos de caballero, botitas de niño, elegantes sandalias... puedo ver con claridad a los seres humanos que los usaron y se parecen enormemente a gente como tú y como yo" Antonio Vallano (2017).

\section{Conclusiones}

Con la frase de Edmund Burke termina el audiovisual del proyecto Auschwitz: El escenario del horror: "Para que triunfe el mal basta con que los hombres de bien no hagan nada". Esta afirmación final invita a la reflexión, la acción y la participación. Desde un enfoque social, la fotografía genera procesos de reflexión y su uso es una herramienta pedagógica que da acceso a diferentes saberes, a compartir diferencias y saber asumirlas, a tener en cuenta que las interpretaciones de cada persona pueden dar lugar a un espacio de diálogo y divergencia y que somos seres humanos que se conmueven con los conflictos y buscan en la mirada un cambio social. En consonancia con Tedesco (2005) la fotografía en general, y el proyecto Auschwitz: El escenario del horror en concreto, ha promovido las siguientes competencias y objetivos educativos en el ámbito informal: 1. La capacidad de abstracción; 2. El pensamiento sistémico; 3. La experimentación y 4. La capacidad de aprender en grupo. (Tedesco, 2005).

Estas competencias se mueven en tres dimensiones importantes (Dussel y Gutiérrez, 2006): el conocimiento, para conocer por qué sucedió el Holocausto; el de la emoción, 
en el que nos conmovemos con el horro de las imágenes y empatizar con el dolor; y la acción, como posibilidad de hacer algo para repararlo y que no suceda en el futuro.

Este proyecto ha sido una oportunidad de conocer las fotografías que son herramientas mediadoras entre el conocimiento y la acción social, con un lenguaje que vive y se nutre de las experiencias, tanto del que las ha realizado, el objeto de dichas tomas y los espectadores. Pero además estas imágenes producen en el ser humano diferentes emociones que pueden ser particularizadas dentro del aprendizaje de un tema como el Holocausto, dando cabida a una reflexión ética, política y cultural, en una relación de aprendizaje y de compartir saberes.

Siguiendo los estudios de Schugurensky (2006) y de otros autores propuestos el aprendizaje informal parece más una construcción externa teórica en la que la propia persona no siempre es consciente cuando se produce incidentalmente 0 en determinadas formas de su vida cotidiana (Rodriguez-Illera y Kaechele, 2009). Este proyecto fotográfico ha seguido, por un lado, el aprendizaje consciente de aquellos que han disfrutado de la exposición y debate de las fotografías; pero por otro, un aprendizaje inconsciente de aquellos participantes que no han acudido explícitamente a dicha exposición, pero que han podido disfrutar de ella en el lugar público en el que se ha encuadrado. La sensibilización frete a un holocausto en épocas pasadas es un aprendizaje inconsciente que puede activar una fotografía. Se necesitan proyectos de este tipo para concienciar sobre los horrores del holocausto, que no se ubiquen únicamente en el Memorial de la Shoah de París, o el Holocaust Memorial Museum en EEUU, ya que son propuestas para la población de todo el mundo.

\section{Agradecimientos}

Agradezco el trabajo incesante y desinteresado de Antonio Vallano, un gran fotógrafo autodidacta que incorpora su trabajo en el mundo académico, agradezco el aprendizaje que nos proporciona con sus fotografías, por su actitud curiosa, por querer conocer el mundo y sus legados patrimoniales. 


\section{Referencias}

Arendt, H. (2003). Eichmann en Jerusalén. Un estudio sobre la banalidad del mal. Lumen.

Asensio, M. (1994). Los autómatas de Hefesto o el procedimiento para crear seres procedimentales. Íber. Didáctica de las Ciencias Sociales, Geografía e Historia, 2, 79-98.

Asensio, M. y Pol, E. (1999). Nuevos escenarios para la interpretación del Patrimonio: el desarrollo de programas públicos. En C. Domínguez, J. Estepa y J. M. Cuenca (Eds.), El Museo: Un espacio para el aprendizaje. (pp. 47-77). Universidad de Huelva.

Asensio, M. y Pol, E. (2001). Nuevos escenarios en educación. Aprendizaje informal sobre el patrimonio, los museos y la ciudad. Aique

Asensio, M. y Pol, E. (2008). Conversaciones sobre aprendizaje informal en museos y patrimonio. En H. Fernández (Ed.), Turismo, Patrimonio y Educación. Los museos como laboratorios de conocimientos y emociones (pp. 19-60). Escuela de Turismo de Lanzarote.

Bauman, Z. (2007). Tempos líquidos. Editora Schwarcz-Companhia das Letras.

Bordieu, P. (2003). Un arte medio. Ensayo sobre los usos sociales de la fotografía. Gustavo Gili.

Clus, M. Le (2011). Informal learning in the workplace: A review of the literature. Australian Journal of Adult Learning, 51(2), 355-373.

Csikszentmihalyi, M. (1975). Beyond boredom and anxiety. Jossey- Bass.

Csikszentmihalyi, M., Abuhamdeh, S. y Nakamura, J. (2005). Flow. En A. J. Elliot y C. S. Dweck (Eds.), Handbook of competence and motivation (pp. 598-608). Guilford Publications.

Cole, Michael (1999). Psicología cultural. Morata.

Deci, E. L. y Moller, A. C. (2005). The concept of competente. En A. J. Elliot y C. S. (Eds.), Handbook of competence and motivation (pp. 579-597). Guilford Publications.

Deci, E. L. y Ryan, M.R. (1991). A motivational approach to self: Integration in personality. En R. Dienstbier (Ed.), Nebraska symposium of motivation. Perspectives on motivation, 38, 237-38.

Deci, E. L. y Ryan, R. M. (1985). Intrinsic motivation and self-determination in human behavior. Plenum Press.

Dussel, I. y Gutiérrez, D. (2006). Educar la Mirada: Políticas y pedagogías de la imagen. Manantial.

Engeström, Y., Miettinen, R. y Punamäki, R.-L. (1999). Perspectives on activity theory. Cambridge University Press.

Gal'perin, P. Y. (1992). Stage-by-stage formation as a method of psychological investigation. Journal of Russian and Eastern European Psychology, 30, 60-80.

Hager, P. y Halliday, J. (2009). Recovering informal learning: Wisdom, judgement and community (Vol. 7). Springer Science \& Business Media.

Hiemstra, R. (1981). The implications of lifelong learning. Museums, Adults and the Humanities, AAM, 120-130.

Knowles, M. S. (1981). The future of lifelong learning. Museums, Adults and the Humanities. AAM.

Leont'ev, Aleksei N. (1972). The problem of activity in psychology. En J. V. Wertsch (Ed.), The concept of activity in Soviet psychology (pp. 37-71). Sharpe. 
Luria, A. R. (1979). Conciencia y lenguaje, Visor, 1984, 2ª ed.

Marsick, V. J. y Watkins, K. (1990). Informal and Incidental Learning in the Workplace. Routledge.

Maclean, R. y Wilson, D. (Eds.) (2009). International handbook of education for the changing world of work: Bridging academic and vocational learning. Springer Science \& Business Media, 1.

Mortimer, E. y Shonick, K. (2010). El Holocausto y la colección de documentos de debate de las Naciones Unidas. https://www.un.org/es/holocaustremembrance/docs/paper11.shtml

Opitz, H. A. (2007). Didáctica Fotográfica. Revista: Experiencias y propuestas en la Construcción del Estilo Pedagógico en Diseño y Comunicación, 7, 236-239.

Rodriguez-Illera, J. L. y Kaechele, M. (2009). Digital Literacy and Activity Systems in Adolescents. En Comparative Information Technology (pp. 89-102). Springer.

Sontag, S. (1996). Sobre la fotografía. Edhasa.

Schugurensky, D. (2006) This is our school of citizenship. En Z. Bekerman, N. C. Burbules, y D. S. Keller (Eds.), Learning in places - the informal education reader. Peter Lang.

Screven, C. G. (1974). The Measurement and Facilitation of learning in the Museum Environment: An Experimental Analysis. Smithsonian Institution Press.

Tedesco, J. C. (2005). La Educación Popular Hoy: Claves para todos. Cl - Capital Intelectual.

UNESCO ONU (2005). Resolución 60/7. https://www.un.org/en/holocaustremembrance/ docs/res607.shtml

VV.AA. (2013). Global Perspectives on Holocaust Edication. Trends, Patterns and Practices. United States Holocaust Memorial and Salzburg Global Seminar. https://holocaust.salzburgglobal.org/fileadmin/ushm/documents/Overview/May2013 GlobalPerspectives final.pdf

Vygotsky, L. (1978). Pensamiento y lenguaje. Paidós. 